\title{
Cytotoxicity of a new antimicrobial coating for surgical screws: an in vivo study
}

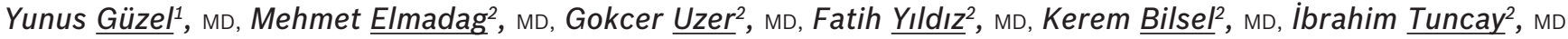

\begin{abstract}
INTRODUCTION The risk of surgery-related infection is a persistent problem in orthopaedics and infections involving implants are particularly difficult to treat. This study explored the responses of bone and soft tissue to antimicrobialcoated screws. We investigated whether such screws, which have never been used to fix bony tissues, would result in a cytotoxic effect. We hypothesised that the coated screws would not be toxic to the bone and that the likelihood of infection would be reduced since bacteria are not able to grow on these screws.

METHODS Titanium screws were inserted into the left supracondylar femoral regions of 16 rabbits. The screws were either uncoated (control group, $\mathrm{n}=8$ ) or coated with a polyvinylpyrrolidone-polyurethane interpolymer with tertiary amine functional groups (experimental group, $n=8$ ). At Week 6 , histological samples were obtained and examined. The presence of necrosis, fibrosis and inflammation in the bony tissue and the tissue surrounding the screws was recorded.

RESULTS Live, cellular bone marrow was present in all the rabbits from the experimental group, but was replaced with connective tissue in four rabbits from the control group. Eight rabbits from the control group and two rabbits from the experimental group had necrosis in fatty bone marrow. Inflammation was observed in one rabbit from the experimental group and five rabbits from the control group.

CONCLUSION Titanium surgical screws coated with polyvinylpyrrolidone-polyurethane interpolymer were associated with less necrosis than standard uncoated screws. The coated screws were also not associated with any cytotoxic side effect.
\end{abstract}

Keywords: antimicrobial coating, coated screws, hydrophobic coating, implant infection

\section{INTRODUCTION}

Although techniques in orthopaedic surgery are continually improving, the risk of infection associated with orthopaedic surgery remains a problem. Infections involving implants are particularly challenging to treat and are associated with high morbidity rates and high monetary costs. ${ }^{(1,2)}$ Treatment for infected implants can range from the use of broad-spectrum antibiotics to the removal of the implant and execution of additional surgeries; all of these therapies involve additional time, money and risks. Although antibiotic-impregnated implants have been reported to successfully prevent infection in orthopaedic patients, there are concerns that the use of such implants may lead to increased bacterial antibiotic resistance. ${ }^{(3-5)}$

Implant infection commences when bacteria adhere to the implant and reproduce to form a biofilm ${ }^{(6)}$ that will, in turn, promote antibiotic resistance; this challenges the immune system and triggers the need for higher doses of antibiotics. ${ }^{(7)}$ Sessile bacteria in biofilms are difficult to identify and treat. Current culture methods were developed to identify the planktonic bacteria of acute infections. However, most of the bacteria in implant-related infections are in a sessile state; that is, although these bacteria are viable, they cannot be cultured. ${ }^{(7-9)}$

Biofilms have received increasing attention in the context of implant infections. Certain agents prevent the bacterial adhesion that is necessary for preliminary biofilm formation, while others corrupt the biofilm structure; some agents can pass through the biofilms to act on both the implant and the bacteria. An antimicrobial coating should ideally prevent bacterial adhesion, and thus halt biofilm formation. Vancomycin, a systemic antimicrobial, is an example of an agent that is able to penetrate biofilms. Antimicrobial peptides can also prevent bacterial adhesion. $^{(3,10)}$

The present study aimed to evaluate the effectiveness of surgical screws coated with a novel antimicrobial that was designed to prevent bacterial adhesion, thus avoiding the formation of a bacterial biofilm. We hypothesised that these screws, which have never been used to fix bony tissues, would not be toxic to the bone and that they would help reduce the likelihood of infection, since bacteria are not able to reproduce on them.

\section{METHODS}

The present study was a small in vivo trial that was conducted using rabbits. All animal procedures were approved by the Institutional Animal Care and Use Committee of our faculty. A total of 16 New Zealand white adult male rabbits, aged 4-7 months and weighing 3,500-4,000 g, were reared in our animal laboratory. Anaesthesia was induced via subcutaneous injection of ketamine $(40 \mathrm{mg} / \mathrm{kg}$ ) and xylazine $(7.5 \mathrm{mg} / \mathrm{kg})$, and was maintained via isoflurane titration. All surgical sites were clipped to remove fur and sterilised with povidone-iodine.

The rabbits were divided into two groups (i.e. the control and experimental groups) of eight. Each rabbit from both groups had

${ }^{1}$ Department of Orthopaedics and Traumatology, School of Medicine, Ordu University, Campus of Cumhuriyet, ${ }^{2}$ Department of Orthopaedics and Traumatology, School of Medicine, Bezmialem Vakıf University, İstanbul, Turkey

Correspondence: Dr Yunus Güzel, Assistant Professor, Ordu University, School of Medicine, Department of Orthopaedics and Traumatology, Campus of Cumhuriyet, 52200 , Centre/Ordu, İstanbul, Turkey. dryg@windowslive.com 
a screw implanted in the supracondylar process of its left femur (Fig. 1) via a lateral incision made using a 2.5-mm-diameter drill. The screws used for both groups measured $2.7 \mathrm{~mm} \times 9 \mathrm{~mm}$. Within each group, the same type of screw was inserted into the left femur of each rabbit. The screws used in the control and experimental groups were standard uncoated titanium screws and antimicrobial-coated titanium screws, respectively. The antimicrobial coating used consisted of polyvinylpyrrolidonepolyurethane interpolymers with non-leaching tertiary amine functional groups (Hydromer Duality EF50L; Hydromer Inc, Branchburg, NJ, USA). ${ }^{(11)}$ This coating minimises the capacity of the bacteria to adhere to the screws and kills the few bacteria that are able to adhere. ${ }^{(12)}$ On exposure to bodily fluids, the bacteria are rapidly killed by the electrostatic interaction between the cationic electrostatic force of the coating and the anionic bacterial outer membrane. ${ }^{(13)}$ This interaction permeabilises the bacterial outer membrane, causing bacterial death. ${ }^{(13)}$

Upon completion of the surgery, all wounds were closed and the rabbits were transferred to cages. All 16 rabbits received buprenorphine $(0.01 \mathrm{mg} / \mathrm{kg})$ and bupivacaine $(1 \mathrm{~mL}, 0.25 \%)$ analgesia prior to the surgery. In addition, all 16 rabbits received postoperative buprenorphine $(0.01 \mathrm{mg} / \mathrm{kg})$; a fentanyl patch was also placed between the shoulders for the first three days after surgery to afford long-term continuous analgesia. The food and water intake of the rabbits was monitored, and free exercise was permitted twice daily. The dressings were changed daily and signs of local infection were noted.

After six weeks, all 16 rabbits were killed via high-dose intracardiac anaesthesia. Samples were taken from 3-cm lengths of all femora (including the surgical sites and the disarticulated distal ends) for histopathological and microbiological examinations. Samples were fixed in 10\% (v/v) formaldehyde for 24-48 hours and, after decalcification in acid, cut into $4-\mu \mathrm{m}$-thick sections, embedded in paraffin blocks and stained with haematoxylin and eosin. Each piece of bone was received in the intramedullary in which it was cultured.

All specimens were evaluated by a pathologist who was blinded to the group assignment of the rabbits. Under a light microscope, the amounts of cortical and trabecular bone were noted. Additionally, the presence of necrosis, fibrosis and inflammation in the bone marrow, periosteum, ligaments and fatty tissue surrounding the screws was evaluated. The extent of necrosis, fibrosis and inflammation in the cortical bone, trabecular bone and bone marrow, and the presence of dead bone fragments was scored as 0 (none), 1 (mild), 2 (moderate) or 3 (severe).

We compared the scores of the two groups using Fisher's exact test. The alpha level was set at 0.05 and all tests were twotailed. MedCalc version 13.0.6.0 (MedCalc Software, Ostend, West Flanders, Belgium) was used for all analyses. The sample number was determined with reference to the expected frequency of bone necrosis (i.e. assuming that $10 \%$ of the experimental group and $90 \%$ of the control group would exhibit necrosis after six weeks). The use of eight rabbits per group afforded an $80 \%$ power to detect this difference (80 percentage points) with a Type I error of 0.05 .
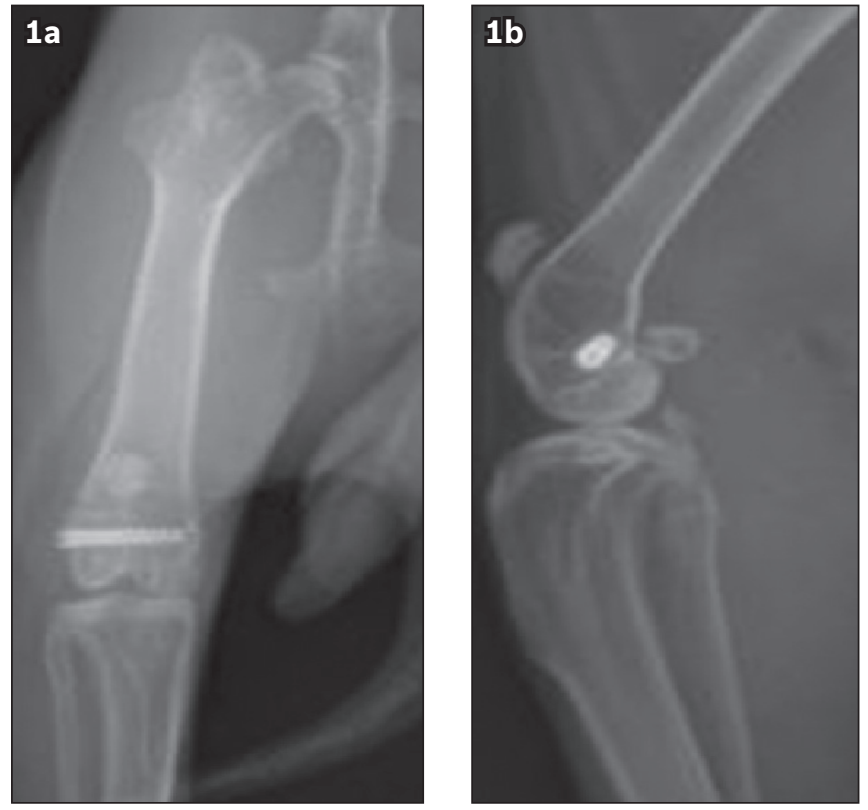

Fig. 1 (a) Anterioposterior and (b) lateral radiographs show a titanium antimicrobial-coated screw in the femur of a six-month-old New Zealand white rabbit.

\section{RESULTS}

All 16 rabbits completed the study protocol. No external sign of infection was evident in any rabbit and none of the cultures grew bacteria. Although connective tissue developed in the bone marrow of four rabbits in the control group, the bone marrow was cellular and alive in all eight rabbits in the experimental group (Table I \& Fig. 2). Necrosis was evident in the fatty bone marrow of all bones from the control group (Fig. 3), but it was evident in only two bones from the experimental group ( $p=0.007$; Table I). In the experimental group, one bone exhibited mild inflammation. In the control group, three bones exhibited mild inflammation and two bones exhibited moderate inflammation (Table I \& Fig. 4). The histopathological scores of the experimental group were significantly better than those of the control group (Table I).

\section{DISCUSSION}

Implants are essential for joint replacement and fracture fixation. However, even when all precautions are taken, implant infection rates range from $1 \%$ to $2 \%$, with higher infection rates reported for internal and external fracture fixations. ${ }^{(2,14)}$ Implant infections are associated with high levels of morbidity and mortality, and high monetary costs. ${ }^{(15,16)}$

An infection commences when bacteria adhere to an implant and reproduce, creating a protective biofilm and rendering diagnosis and treatment difficult. ${ }^{(6-9)}$ Thus far, efforts to prevent biofilm formation have involved the use of antibiotic cement, antibiotic coatings and other materials that inhibit bacterial reproduction. ${ }^{(1,3,17)}$ As antibiotic cement cannot be used in all joint replacements, there is increased interest in the development of other materials that inhibit bacterial reproduction on implants. ${ }^{(4,18)}$ Such materials include silver and silver compounds, selenium and antimicrobial peptides. ${ }^{(5,17-20)}$ Silver- or selenium-coated implants are effective ${ }^{(20,21)}$ but expensive; furthermore, the use 
Table I. Comparison of the bone and tissue effects of uncoated titanium surgical screws and antimicrobial-coated titanium surgical screws six weeks after implantation in white rabbits.

\begin{tabular}{|c|c|c|c|}
\hline \multirow[t]{2}{*}{ Variable } & \multicolumn{2}{|c|}{ No. } & \multirow[t]{2}{*}{ p-value } \\
\hline & $\begin{array}{l}\text { Control group } \\
\quad(n=8)\end{array}$ & $\begin{array}{l}\text { Experimental } \\
\text { group }(n=8)\end{array}$ & \\
\hline Cortical bone & & & 0.47 \\
\hline Irregular & 6 & 8 & \\
\hline Active bone structure & 2 & 0 & \\
\hline Trabecular bone & & & 0.20 \\
\hline Porotic and irregular & 5 & 8 & \\
\hline Active bone structure & 3 & 0 & \\
\hline $\begin{array}{l}\text { Fibrosis in areas of bone } \\
\text { marrow }\end{array}$ & & & 0.08 \\
\hline Cellular and alive & 4 & 8 & \\
\hline $\begin{array}{l}\text { Moderate/evident } \\
\text { development of } \\
\text { connective tissue }\end{array}$ & 4 & 0 & \\
\hline Necrosis & & & 0.007 \\
\hline None & 0 & 6 & \\
\hline $\begin{array}{l}\text { In areas of fatty bone } \\
\text { marrow }\end{array}$ & 8 & 2 & \\
\hline Inflammation & & & 0.12 \\
\hline None & 3 & 7 & \\
\hline Mild/moderate & 5 & 1 & \\
\hline Dead bone fragments & & & 0.99 \\
\hline None & 7 & 8 & \\
\hline Present & 1 & 0 & \\
\hline
\end{tabular}

of such implants has been reported to result in cytotoxic side effects. ${ }^{(17,19,20)}$ Thus, non-toxic and cost-effective substances are being developed. ${ }^{(17,19,20,22)}$ Broad-spectrum antimicrobial peptides can be used to destroy bacterial membranes, but these peptides are currently difficult and expensive to produce. ${ }^{(10}$

The major limitation of the present study is that it did not assess chronic toxicity. As the coating was neither absorbable nor soluble ${ }^{(11,13)}$ and no bacterial growth was observed, we did not screen blood samples for evidence of infection. In this evaluation of the potential cytotoxicity of a new antimicrobial coating for surgical screws in an animal model, we hypothesised that the screws would not be toxic to bone and that the likelihood of infection would be reduced since bacteria could not reproduce on the screws. The results (i.e. the lack of bony necrosis and lower levels of inflammation, necrosis and fibrosis in the experimental group) provided evidence that the coated screws were not cytotoxic. The coated screws were, however, associated with slightly poorer cortical and trabecular bone responses, but the between-group difference was not found to be statistically significant.

The antimicrobial coating was made of polyvinylpyrrolidonepolyurethane interpolymer featuring non-lysing tertiary amine functional groups. This coating has been shown to inhibit bacterial adhesion. ${ }^{(13)}$ When the coating is exposed to bodily fluids, bacteria are destroyed by the electrostatic interaction between the cationic coating and the anionic bacterial outer membrane. This interaction increases the permeability of the bacterial outer membrane, damaging the membrane and killing the bacteria. ${ }^{(13)}$

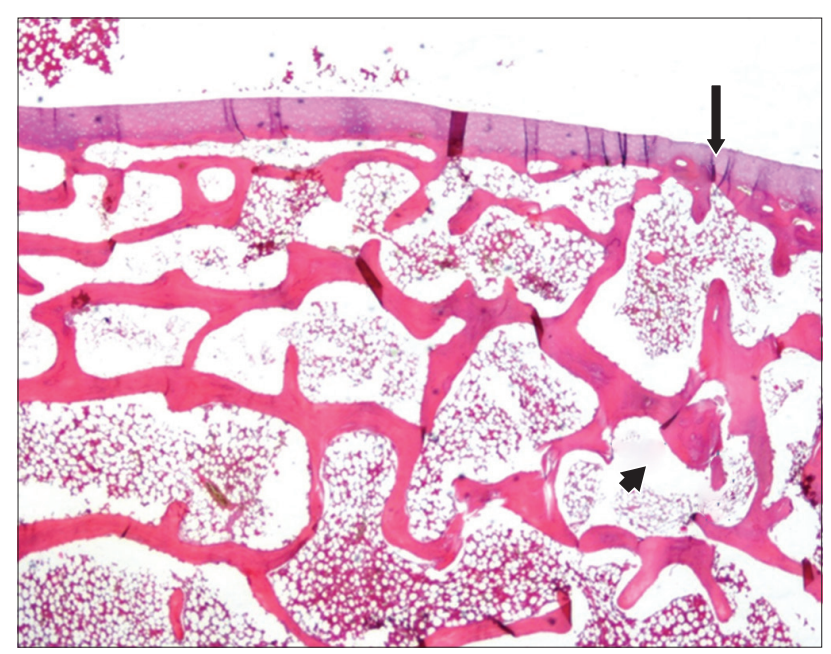

Fig. 2 Photomicrograph of cellular bone marrow obtained from the femur of a New Zealand white rabbit six weeks after the implantation of a antimicrobial-coated titanium surgical screw shows normal cortex (arrow) and trabecular bone (arrowhead) (Haematoxylin \& eosin, $\times 40)$.

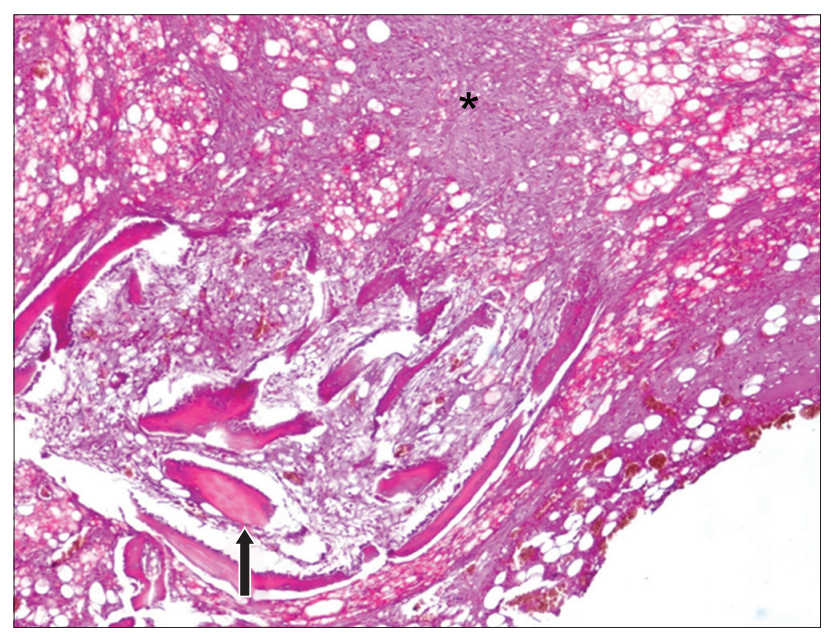

Fig. 3 Photomicrograph of cellular bone marrow obtained from the femur of a New Zealand white rabbit six weeks after the implantation of a standard uncoated titanium surgical screw shows dense fibrosis, inflammation (asterisk) and bone structure (arrow) (Haematoxylin \& eosin, × 40).

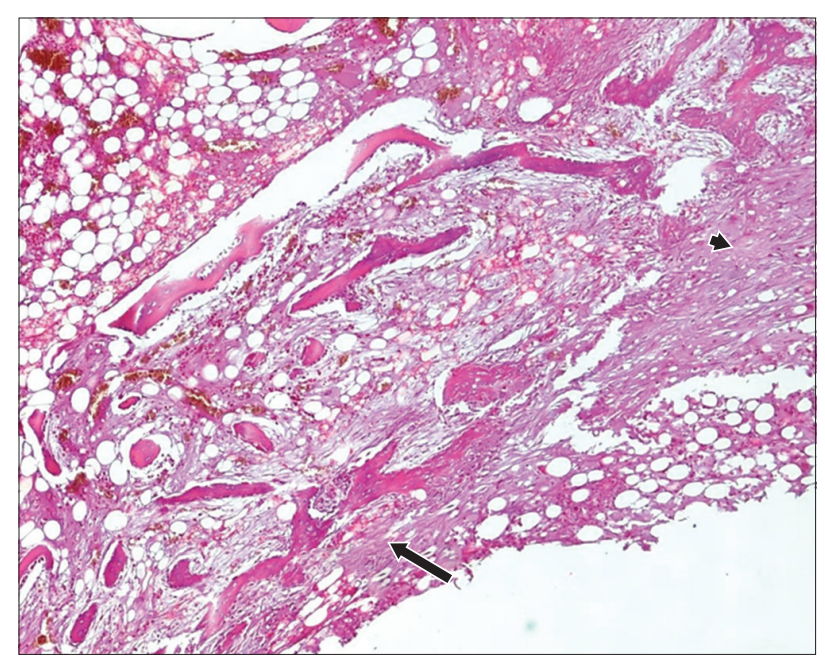

Fig. 4 Photomicrograph of cellular bone marrow obtained from the femur of a New Zealand white rabbit six weeks after the implantation of a standard uncoated titanium surgical screw shows dense inflammation and fibrous tissue formation around the screw (arrowhead), and areas of partly woven bone surrounded by osteoblasts (arrow) (Haematoxylin \& eosin, $\times 40$ ). 
Selenium, which is a basic trace element, inhibits bacterial adhesion, and thus implant infections, by catalysing the formation of superoxide $\left(\mathrm{O}_{2}^{-}\right)$radicals. ${ }^{(19,20,23)}$ Although selenium has been shown to significantly reduce the adhesion of Staphylococcus epidermidis (S. epidermidis) and Staphylococcus aureus (S. aureus) to titanium discs, its antimicrobial effect remains to be established. ${ }^{(19)}$

Stewart et $\mathrm{al}^{(24)}$ fixed sheep tibial fractures with vancomycincoated titanium plates and infected the fractures with $S$. aureus. After three months, the authors observed that the vancomycin coating had inhibited $S$. aureus colonisation and supported bone formation. ${ }^{(24)}$ Even though two studies by Antoci et al ${ }^{(25,26)}$ reported that $S$. epidermidis did not become resistant to vancomycin, a study by Darouiche et $\mathrm{al}^{(27)}$ showed that vancomycin was not able to inhibit the growth of $S$. epidermidis to the extent desired. It is possible that the vancomycin could not effectively penetrate the biofilm, as local antibiotic levels are often lower than the minimal inhibitory concentrations. ${ }^{(24,28)}$ In such a situation, the bacteria become antibiotic-resistant by undergoing sensory changes and modulating gene expression. ${ }^{(28)}$

While the development of bacterial resistance to antibiotic coatings (e.g. gentamicin and tobramycin) remains to be evaluated, silver coatings have been shown to be both costly

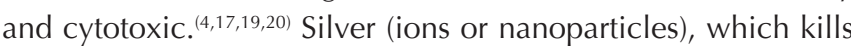
bacteria by attacking the thiol groups of the extracellular domains of membrane proteins, has been shown to be toxic to eukaryotic cells in vitro. The nanoscale dimension is a risk factor for dosedependent cell death, as no physical barrier prevents nanoparticle uptake by cells. ${ }^{(29)}$

Since the antimicrobial coating used in our study did not use antibiotics, concerns regarding bacterial mutation, adaptation and resistance to antibiotics were not relevant. The antimicrobial coating used in our study permanently covers the surface of the screw and protects it from contact with bodily fluids. As the coating is neither absorbable nor soluble, bacterial growth is inhibited. ${ }^{(11,13)}$ The nanoparticle problem associated with silver coatings is also not relevant to this antimicrobial coating. As bacterial adhesion is not relevant, the effective dose requirements of antibiotic therapy or silver therapy are not of concern. Furthermore, the bactericidal process of the antimicrobial coating used in our study continues for as long as bodily fluids remain in contact with the implant.

To conclude, the findings of the present study provided evidence that titanium surgical screws coated with the polyvinylpyrrolidone-polyurethane interpolymer are associated with less necrosis than standard uncoated screws. The coated screws were also shown to not have cytotoxic side effects. It should be noted that less necrosis is not synonymous with reduced infection. Thus, further studies on polyvinylpyrrolidonepolyurethane interpolymer-coated screws and the effect of the use of these screws on infection rates are warranted.

\section{REFERENCES}

1. Gilchrist SE, Lange D, Letchford K, et al. Fusidic acid and rifampicin co-loaded PLGA nanofibers for the prevention of orthopedic implant associated infections. J Control Release 2013; 170:64-73.

2. Zimmerli W, Trampuz A, Ochsner PE. Prosthetic-joint infections. N Engl J Med 2004; 351:1645-54.
3. Jose B, Antoci V Jr, Zeiger AR, Wickstrom E, Hickok NJ. Vancomycin covalently bonded to titanium beads kills Staphylococcus aureus. Chem Biol 2005; 12:1041-8.

4. Anguita-Alonso P, Hanssen AD, Osmon DR, et al. High rate of aminoglycoside resistance among staphylococci causing prosthetic joint infection. Clin Orthop Relat Res 2005; 439:43-7.

5. Bai X, More K, Rouleau CM, Rabiei A. Functionally graded hydroxyapatite coatings doped with antibacterial components. Acta Biomater 2010; 6:2264-73.

6. Arciola CR, Campoccia D, Speziale P, Montanaro L, Costerton JW. Biofilm formation in Staphylococcus implants infections. A review of molecular mechanisms and implications for biofilm resistant materials. Biomaterials 2012; 33:5967-82.

7. Zameer F, Gopal S. Evaluation of antibiotic susceptibility in mixed culture biofilms. Int J Biotech Biochem 2010; 6:93-9.

8. Hill KE, Malic S, McKee R, et al. An in vitro model of chronic wound biofilms to test wound dressings and assess antimicrobial susceptibilities. J Antimicrob Chemother 2010; 65:1195-206.

9. Palmer M, Costerton W, Sewecke J, Altman D. Molecular techniques to detect biofilm bacteria in long bone nonunion: a case report. Clin Orthop Relat Res 2011; 469:3037-42.

10. Romanò CL, Toscano M, Romanò D, Drago L. Antibiofilm agents and implant-related infections in orthopaedics: where are we? J Chemother 2013; 25:67-80

11. Kristinsson KG. Adherence of staphylococci to intravascular catheters. J Med Microbiol 1989; 28:249-57.

12. Bayston R, Bhundia C, Ashraf W. Hydromer-coated catheters to prevent shunt infection? J Neurosurg 2005; 102(2 Suppl):207-12.

13. Bridgett MJ, Davies MC, Denyer SP, Eldridge PR. In vitro assessment of bacterial adhesion to Hydromer-coated cerebrospinal fluid shunts. Biomaterials 1993; 14:184-8.

14. Canadian Orthopaedic Trauma Society. Open reduction and internal fixation compared with circular fixator application for bicondylar tibial plateau fractures. Results of a multicenter, prospective, randomized clinical trial. J Bone Joint Surg Am 2006; 88:2613-23.

15. Calhoun JH, Manring MM. Adult osteomyelitis. Infect Dis Clin North Am 2005; 19:765-86.

16. Kurtz SM, Lau E, Watson H, Schmier JK, Parvizi J. Economic burden of periprosthetic joint infection in the United States. J Arthroplasty 2012; 27(8 Suppl):61-5.e1.

17. Zhao L, Chu PK, Zhang Y, Wu Z. Antibacterial coatings on titanium implants. J Biomed Mater Res B Appl Biomater 2009; 91:470-80.

18. Ambrose CG, Clyburn TA, Mika J, et al. Evaluation of antibioticimpregnated microspheres for the prevention of implant-associated orthopaedic infections. J Bone Joint Surg Am 2014; 96:128-34.

19. Holinka J, Pilz M, Kubista B, Presterl E, Windhager R. Effects of selenium coating of orthopaedic implant surfaces on bacterial adherence and osteoblastic cell growth. Bone Joint J 2013; 95-B:678-82.

20. Wang Q, Webster TJ. Nanostructured selenium for preventing biofilm formation on polycarbonate medical devices. J Biomed Mater Res A 2012; 100:3205-10.

21. Kose N, Otuzbir A, Pekşen C, Kiremitçi A, Doğan A. A silver ion-doped calcium phosphate-based ceramic nanopowder-coated prosthesis increased infection resistance. Clin Orthop Relat Res 2013; 471:2532-9.

22. Wimley WC. Describing the mechanism of antimicrobial peptide action with the interfacial activity model. ACS Chem Biol 2010; 5:905-17.

23. Hockin SL, Gadd GM. Linked redox precipitation of sulfur and selenium under anaerobic conditions by sulfate-reducing bacterial biofilms. Appl Environ Microbiol 2003; 69:7063-72.

24. Stewart S, Barr S, Engiles J, et al. Vancomycin-modified implant surface inhibits biofilm formation and supports bone-healing in an infected osteotomy model in sheep: a proof-of-concept study. J Bone Joint Surg Am 2012; 94:1406-15

25. Antoci V Jr, Adams CS, Parvizi J, et al. Covalently attached vancomycin provides a nanoscale antibacterial surface. Clin Orthop Relat Res 2007; 461:81-7.

26. Antoci V Jr, Adams CS, Hickok NJ, Shapiro IM, Parvizi J. Vancomycin bound to Ti rods reduces periprosthetic infection: preliminary study. Clin Orthop Relat Res 2007; 461:88-95.

27. Darouiche RO, Dhir A, Miller AJ, et al. Vancomycin penetration into biofilm covering infected prostheses and effect on bacteria. J Infect Dis 1994; 170:720-3.

28. Reading NC, Sperandio V. Quorum sensing: the many languages of bacteria. FEMS Microbiol Lett 2006; 254:1-11

29. Hussain SM, Hess KL, Gearhart JM, Geiss KT, Schlager JJ. In vitro toxicity of nanoparticles in BRL 3A rat liver cells. Toxicol In Vitro 2005; 19:975-83. 